\title{
When adherence to CPAP fails, how do we treat workers with obstructive sleep apnea?
}

Maria de Lourdes Rabelo Guimarães ${ }^{1}$ Pedro Guimarães Azevedo ${ }^{1}$ Sérgio Barros-Vieira ${ }^{2}$

Maxime Elbaz ${ }^{3}$

Damien Leger ${ }^{4}$

Ana Paula Hermont ${ }^{5 *}$

${ }^{1}$ Universidade Federal de Minas Gerais, Faculty of Medicine, Belo Horizonte, Brazil, - Belo Horizonte - Minas Gerais - Brazil. ${ }^{2}$ UNISONO- Centre de Diagnostique et Traitement des Troubles du Sommeil, Vitória - Espírito Santo - Brazil.

Université Paris Descartes, Sorbonne Paris Cité, EA, Vigilance Fatigue Sommeil et Santé Publique - Paris - Paris - France. ${ }^{4}$ Hôtel-Dieu, centre du Sommeil et de la Vigilance, Consultation de pathologie professionnelle Sommeil Vigilance et Travail, - Paris - Paris - France.

${ }^{5}$ Universidade Federal de Minas Gerais, Faculty of Dentistry, Belo Horizonte, Brazil, - Belo Horizonte - Minas Gerais Brazil.

\author{
*Corresponding author: \\ Ana Paula Hermont \\ E-mail: anapaulahermont@gmail.com
}

Received: May 13, 2021;

Accepted: August 17, 2021.

\begin{abstract}
Aims: A cross-sectional study was designed to evaluate the effectiveness of a mandibular advancement device (MAD) with respect to respiratory and sleep parameters among miners with obstructive sleep apnea syndrome (OSAS) and primary snore.

Methods: The target sample was composed by 102 Brazilian miners with a history of non-adherence to continuous positive airway pressure. All patients were treated with a MAD and underwent pre and post-treatment full-night polysomnography. Ethical approval and consents were obtained. Bivariate and logistic regression analyses were conducted. The level of statistical significance was set at $5 \%$.

Results: After the treatment with MAD, $71.8 \%$ of patients presented a decrease $\geq 50 \%$ in the basal apnea-hypopnea index (AHI), 51.2\% presented an AHI $<5$ events $/ \mathrm{h}$ and $83.3 \%$ reached an $\mathrm{AHI}<10 / \mathrm{h}$, whereas $22.5 \%$ did not show any changes and $7.5 \%$ of the sample presented an increase in the AHI $(\mathrm{p}<0.05)$. There was an increase in the mean SpO2 nadir $(\mathrm{p}<0.001)$ and in the baseline duration of the REM sleep stage $(\mathrm{p}<0.05)$. The MAD significantly decreased snore events $(\mathrm{p}<0.05)$. Multivariate analysis did not identify predictive factors related to therapy success (decrease $\geq 50 \%$ of $\mathrm{AHI}$ ). However, basal $\mathrm{AHI}$ was a significant predictor related to the secondary endpoint $(\mathrm{AHI}<10 / \mathrm{h})(\mathrm{OR}=1.06$, IC 95\%1.00-1.13, $\mathrm{p}=0.007)$.

Conclusions: The MAD therapy showed significant improvements in AHI, minimum oxygen saturation, REM sleep and snoring.
\end{abstract}

Keywords: Oral Appliances; Mandibular Advancement Device; Obstructive Sleep Apnea; Occupational Medicine; Prevention Of Accidents. 


\section{INTRODUCTION}

Mining has always been among the most dangerous occupations, and with the growing demand for minerals, mine safety assumes even greater importance ${ }^{1}$. Traumatic injuries in mining remain a significant problem ranging from trivial to fatal injuries ${ }^{2}$. Sleep appears to be a much easier way to determine if a worker is tired, and fatigue presents several challenges for the mining industry ${ }^{3}$. Miners may have poorer sleep quality and less sleep efficiency compared to the general population of the same age, with nearly 40 to 60 minutes less bed time and total sleep time before starting the day shift ${ }^{4}$.

Obstructive Sleep Apnea Syndrome (OSAS) is characterized by continuous collapses of the superior airway during sleep, associated with nocturnal hypoxemia and sleep fragmentation ${ }^{5}$. Brain dysfunctions might also manifest, such as excessive daytime sleepiness and lack of concentration. These are the most common causes of traffic accidents ${ }^{6}$. OSAS compromises professional activities leading workers to higher risks of occupational accidents $^{7,8}$, increasing the incidence of illness and decreasing worker's productivity ${ }^{9}$.

In North America, OSAS's prevalence varies from 20 to $30 \%$ in men and 10 to $15 \%$ in women when it is defined as an apnea-hypopnea index (AHI) higher than five events per hour ${ }^{10}$. In Canada, the evaluation of mine workers subjected to polysomnographic exams showed that the most fatigued individuals presented significantly more sleep pathologies than less fatigued workers ${ }^{11}$. OSAS was the most prevalent sleep disorder in the fatigued workers ${ }^{12}$. In Turkey, a statistically significant correlation between Epworth Sleepiness Scale (ESS) and work-related accidents has been found. However, the prevalence of OSAS symptoms in miners was similar to the general population ${ }^{13}$. In Brazil, a study conducted in 2010 showed an OSAS's prevalence of $32 \%$ in general population and $30.1 \%$ in workers ${ }^{14}$.

OSAS treatment could decrease the number of workrelated accidents and improve work performance ${ }^{6,8}$. Studies have shown that treatment with continuous positive airway pressure (CPAP) devices can markedly reduce the risk of accidents ${ }^{15}$, however, there is a lack of studies evaluating the effectiveness of oral appliances (OA) in occupational field.

CPAP is considered the first-line treatment for patients with moderate or severe OSAS associated with somnolence ${ }^{16}$. Nevertheless, the adherence rate to CPAP is problematic ${ }^{17}$, since 46 to $83 \%$ of patients do not use CPAP for more than four hours a day, leading to the need of alternative treatments ${ }^{18,19}$. OA have emerged as an alternative to CPAP therapy, the most commonly used OA reduce upper airway collapses by advancing the mandible and they are known as mandibular advancement devices $(\mathrm{MAD})^{20}$. OA improve subjective somnolence and the rates of sleep respiratory disturbances in patients with OSAS $^{9,21}$. Studies comparing both therapies have shown that MAD present effects similar to the gold-standard CPAP treatment in improving cognitive development and decreasing excessive daytime sleepiness ${ }^{9,22}$.

Moreover, patients often prefer MAD to CPAP treatment, and the superiority of CPAP in reducing OSAS parameters on polysomnography does not necessarily result in better health outcomes in clinical practice. Comparable effectiveness of MAD and CPAP has been attributed to higher MAD compliance. Therefore, despite being less effective in reducing apneic events, MAD may be counteracted by greater treatment adherence ${ }^{23}$. The aim of this study was to evaluate the effectiveness of a MAD with respect to respiratory and sleep parameters among Brazilian miners with obstructive sleep apnea. Predictors of success were also evaluated.

\section{MATERIAL AND METHODS}

\section{Ethical issues}

The study was conducted according to the principles of the Helsinki Declaration and received the approval of the Internal Review Board of Hospital Felício Rocho BH-MG (CAAE - 0002.0.240.000-11). Patients' consents were obtained from the entire sample.

\section{Participants}

The present sample was composed by 102 miners suffering from primary snoring and/or OSAS who presented a history of non-adherence to CPAP. Those miners were referred by sleep specialists for dental clinic specialized in the treatment of OSAS with MAD. Data collection occurred between October of 2016 and December of 2017. All miners who were referred to the dental clinic during this period and attended the eligibility criteria $(n=102)$ were invited to take part in the study.

\section{Eligibility criteria}

The including criteria were: age $\geq 18$ years-old; primary snoring or OSAS (AHI $>5 / \mathrm{h}$ ) during polysomnography (PSG); refusal or non-adherence to CPAP (due to pressure intolerance, skin irritation, mask leak with secondary sleep disturbance, claustrophobia, aerophagia, compliance $<3 \mathrm{~h} /$ night). All patients underwent detailed clinical examination to evaluate whether they fit the primary or secondary indications for the therapy with MAD.

The exclusion criteria were defined as: central apnea index $\geq 5 / \mathrm{h}$, severe sleep comorbidities other than OSAS or coexistent psychiatric diseases, patients with insufficient number of teeth for fitting the MAD, active periodontitis and acute temporomandibular disorders (TMD).

\section{Polysomnography}

All patients were submitted to two full-night polysomnography recordings (basal and after-treatment). 
All exams were conducted at the same sleep laboratory under the supervision of a capacitated technician and the reports were written by Sleep Medicine physicians and the exams were conducted accordingly to the American Academy of Sleep Medicine ${ }^{24}$.

Obstructive apnea was defined as a pause $\geq 10$ seconds of the air in the nasal cannula and the thermistor. Hypopnea was defined as a decrease in airflow of $\geq 30 \%$ (by a valid measure of airflow) lasting $\geq 10 \mathrm{~s}$, associated with either $\geq 3 \%$ desaturation from the pre-event baseline or an arousal. The AHI was defined as the number of apneas plus hypopneas per hour of sleep.

The exams with the MAD in situ were performed at least three months after the OA was fitted and after it had been optimally titrated. When the therapy did not present response rates (a decrease in the AHI $>50 \%$ when compared to the basal index and/or persistent symptoms), the MAD was titrated again, and a PSG was performed after a six-month period.

\section{Intervention: mandibular advancement device}

Each patient was treated with a MAD: LateralProtrusive Plaque ${ }^{\circledR}$ (PLP) (Figure 1). PLP is a mandibular advancement device developed by one of the authors (MLRG) and consists of two encapsulated acrylic plates retained by the two arcades through retaining clamps providing complete occlusal coverage ${ }^{25,26}$. Maxillary and mandibular plaques are connected by an adjustable screw that allows progressive protrusion of the mandibular component in increments of $0.25 \mathrm{~mm}$, comprising a total of $11 \mathrm{~mm}$ in anteroposterior movement.

The appliance is fitted with an initial advancement of $50 \%$ of the patient maximum mandibular protrusion. The therapy is conducted by qualified dentists and the appliance is titrated according to the dentist criteria, respecting the patient's tolerability and their reports related to symptoms improvements. After reaching optimal titration (at least 3 months after fitting the MAD), full-night PSG recordings must be performed to check therapy effectiveness.

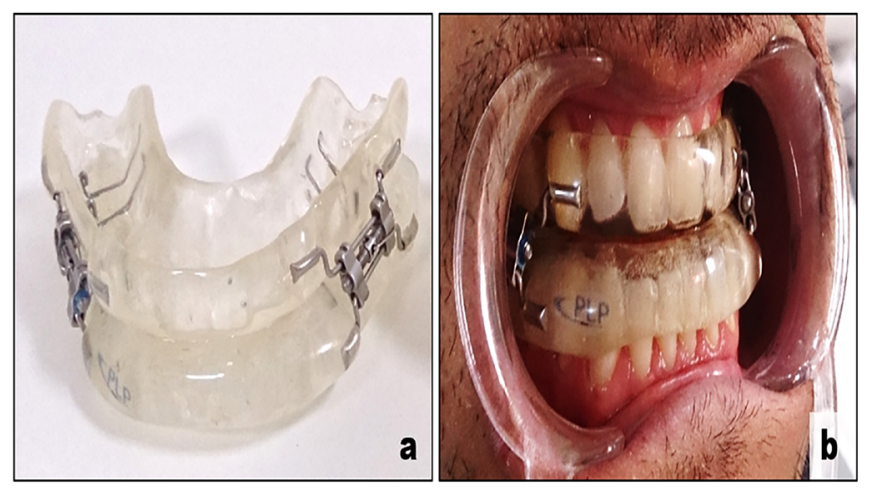

Figure 1. Mandibular advancement device (a); mandibular advancement device in situ (b).

\section{Endpoints}

The first endpoint was the therapy response rate, which was defined as a decrease $\geq 50 \%$ in the AHI. The second endpoint was the evaluation of a complete treatment response defined by an AHI after-treatment: $<5$ events/h or $<10$ events/h. Patients who achieved response rates were encouraged to continue treatment until they reached a complete response.

\section{Evaluated parameters}

Sleep and respiratory parameters were recorded before the treatment and during the follow-up visits. All patients were referred to the same sleep laboratory for diagnosis and monitoring the therapy with the MAD in situ. The independent variables evaluated were: 1) sleep parameters (snore, N3 and REM sleep percentage, arousal index, sleep effectiveness, sleep bruxism); 2) respiratory parameters (AHI, mean and minimum $\mathrm{SpO}_{2}$ ); 3) dental parameters (sleep bruxism and malocclusion); 4) sociodemographic parameters (sex, age, work hours/shift); 5) general health parameters (presence of comorbidities); 6) tolerability, adherence and side effects related to the therapy were evaluated by self-report questionnaires.

\section{Statistical analysis}

Statistical analyses were performed using the SPSS software package (version 25.0 for Windows; SPSS Chicago, IL, USA). Data is expressed as frequency, median and range. Mean and standard deviation were the measures used for data following normal distribution. Basal and after-treatment AHI values were categorized as: 1) Normal $(\mathrm{AHI}<5$ events $/ \mathrm{h})$; 2) Mild (AHI $=5-15$ events $/ \mathrm{h}) ; 3)$ Moderate $(\mathrm{AHI}=16-30$ events/h); 4) Severe (AHI $>30$ events/h) and compared using Marginal Homogeneity Test and bivariate analysis (Qui-square test). Mean values for $\mathrm{SpO}_{2}$ were compared before and aftertreatment using the t-paired test. A logistic regression analysis was used to determinate the independent factors associated with the effectiveness of the treatment. The level of statistical significance was $5 \%(\mathrm{p} \leq 0.05)$.

\section{RESULTS}

Demographic, anthropometric and baseline clinical parameters

One hundred and two mine workers were referred to the therapy with MAD. Twenty-two $(21.6 \%)$ could not be treated with the MAD due to the following reasons: acute TMD, craniofacial dimorphism and compromised periodontal condition. Therefore, 80 patients were included and treated with the MAD. The sample's mean age was $46.24 \pm 8.69$ years, being $67(83.8 \%)$ men and $13(16.2 \%)$ women. Patients' sociodemographic data and their baseline clinical profile are shown in Table 1. 
Table 1. Sociodemographic data, baseline clinical profile and respiratory status of the sample.

\begin{tabular}{|c|c|}
\hline Parameters & Baseline data \\
\hline \multicolumn{2}{|l|}{ Sociodemographic data } \\
\hline Gender (male/ female), n (\%) & $67(83.8) / 13(16.2)$ \\
\hline Age (years) (mean $\pm \mathrm{SD})$ & $46.24 \pm 8.69$ \\
\hline \multicolumn{2}{|l|}{ Working Time } \\
\hline Shift work, $\mathrm{n}(\%)$ & $49(61.2)$ \\
\hline Day shift, n (\%) & $31(38.8)$ \\
\hline \multicolumn{2}{|l|}{ Respiratory and sleep parameters } \\
\hline $\mathrm{AHI}^{*} / \mathrm{h}($ mean $\pm \mathrm{SD})$ & $16.48 \pm 13.02$ \\
\hline $\mathrm{AI} * * / \mathrm{h}($ mean $\pm \mathrm{SD})$ & $1.35 \pm 1.06$ \\
\hline $\mathrm{HI}^{* * *} / / \mathrm{h}($ mean $\pm \mathrm{SD})$ & $14.40 \pm 12.59$ \\
\hline $\mathrm{SpO} 2^{* * * *}($ mean $\pm \mathrm{SD})$ & $94.38 \pm 0.78$ \\
\hline $\mathrm{SpO} 2^{* * * *}$ nadir $($ mean $\pm \mathrm{SD})$ & $86.33 \pm 1.53$ \\
\hline Arousal index $/ \mathrm{h}($ mean $\pm \mathrm{SD})$ & $20.93 \pm 11.02$ \\
\hline Sleep bruxism, n (\%) & $21(26.3)$ \\
\hline \multicolumn{2}{|l|}{ Angle's malocclusion } \\
\hline Class I, n (\%) & $26(32.5)$ \\
\hline Class II, n (\%) & $25(31.3)$ \\
\hline Class III, n (\%) & $29(36.2)$ \\
\hline \multicolumn{2}{|l|}{ General health status } \\
\hline Hypertension, n (\%) & $14(17.5)$ \\
\hline Diabetes, n (\%) & $2(2.5)$ \\
\hline Thyroid alterations, n (\%) & $1(1.3)$ \\
\hline Emotional alterations, n (\%) & $9(11.3)$ \\
\hline Decrease in libido, $\mathrm{n}(\%)$ & $1(1.3)$ \\
\hline Pulmonary condition, $\mathrm{n}(\%)$ & $4(5.0)$ \\
\hline
\end{tabular}

AHI: apnea-hypopnea index; ** AI: apnea index; *** HI: hypopnea index; **** SpO2 oxygen saturation.

\section{MAD's titration}

At least $5 \pm 2$ titrations were required to achieve the optimal MAD titration and the time interval between fitting the OA and the monitoring PSG exam with the MAD in situ was $6 \pm 3$ months. The mean total amount of mandibular advancement was $7.0 \pm 1.36 \mathrm{~mm}$.

\section{Effectiveness}

Primary endpoint: $71.8 \%$ of patients presented a decrease $\geq 50 \%$ in the AHI after-treatment. Secondary endpoint: complete answers to treatment were detected among $83.3 \%$ of the patients $(\mathrm{AHI}<10 / \mathrm{h})$ and $51.2 \%(\mathrm{AHI}<5 / \mathrm{h})$. In summary, after the treatment with the MAD, $70 \%$ of the patients presented an improvement in the AHI, $22.5 \%$ did not show any changes and $7.5 \%$ of the sample presented an increase in the AHI ( $\mathrm{p} \leq 0.05)$.

Table 2 shows the comparison of the sample according to the severity of apnea before and after treatment with the MAD in absolute number and percentage. The parameters adopted with respect to AHI are: normal (patients with AHI < 5events/h), mild (AHI from 5.0 to $14.9 / \mathrm{h}$ ), moderate $(15.0$ to $29.9 / \mathrm{h}$ ) and severe (> 30/h). There was a statistically significant reduction in the AHI after treatment, showing a significant improvement in apnea severity (Table 2).
Table 2. Comparison of the sample according to the apnea-hypopnea index (AHI) severity before and after treatment with the mandibular advancement device.

\begin{tabular}{|c|c|c|c|}
\hline AHI Severity & $\begin{array}{c}\text { Baseline } \mathrm{n} \\
(\%)^{*}\end{array}$ & $\begin{array}{c}\text { After treatment } \\
\text { n }(\%)^{*}\end{array}$ & $\mathrm{p}$ values $* *$ \\
\hline Normal & $8(10.0)$ & $41(51.2)$ & $<0.001$ \\
\hline Mild & $38(47.5)$ & $32(40.0)$ & $<0.001$ \\
\hline Moderate & $21(26.3)$ & $3(3.8)$ & $<0.001$ \\
\hline Severe & $13(16.2)$ & $4(5.0)$ & $<0.001$ \\
\hline Total & $80(100.0)$ & $80(100.0)$ & \\
\hline
\end{tabular}

$*_{\mathrm{n}}(\%)$ refers to the number of patients; ${ }^{* *}$ Qui-square test.

A more detailed analysis of patients' improvement according to apnea severity based on the $\mathrm{AHI}$ is presented in Table 3. Among the patients with mild baseline AHI $(\mathrm{n}=38), 65.7 \%$ presented normal AHI after treatment and only $7.8 \%$ presented worse values after therapy with MAD. All patients with moderate baseline AHI $(n=21)$ presented an improvement, since $42.9 \%$ presented normal AHI and $57.1 \%$ presented mild AHI after treatment. Finally, among patients with a severe baseline AHI ( $n=13), 10(76.9 \%)$ presented a decrease in the index after treatment (Table 3).

Table 3. Patients' distribution according to the severity of apnea-hypopnea index (AHI) before and after treatment with mandibular advancement device.

\begin{tabular}{llll|ll}
\hline & & \multicolumn{4}{c}{ Post-treatment } \\
\cline { 3 - 6 } Baseline AHI n (\%)* & $\begin{array}{l}\text { Normal } \\
\text { n (\%) }\end{array}$ & $\begin{array}{l}\text { Mild } \\
\text { n (\%)* }\end{array}$ & $\begin{array}{l}\text { Moderate } \\
\text { n (\%)* }\end{array}$ & $\begin{array}{l}\text { Severe } \\
\text { n (\%)* }\end{array}$ \\
\hline Normal n (\%) & $8(100.0)$ & $5(62.5)$ & $3(37.5)$ & 0 & 0 \\
\hline $\begin{array}{l}\text { Mild n (\%) } \\
\text { Moderate n }\end{array}$ & $38(100.0)$ & $25(65.7)$ & $\begin{array}{l}10 \\
(26.3)\end{array}$ & $2(5.2)$ & $1(2.6)$ \\
$\begin{array}{l}(\%) \\
\text { Severe n (\%) }\end{array}$ & $13(100.0)$ & $2(15.4)$ & $\begin{array}{l}12 \\
(57.1)\end{array}$ & 0 & 0 \\
Total & $80(100.0)$ & $41(51.3)$ & $\begin{array}{l}32 \\
(40.0)\end{array}$ & $3(3.7)$ & $3(23.1)$ \\
\hline
\end{tabular}

$*_{\mathrm{n}}(\%)$ refers to the number of patients.

\section{Oxygen saturation and sleep related data}

The average of minimum $\mathrm{SpO}_{2}$ increased from $84.0 \pm 5.9$ to $86.9 \pm 5.4(95 \%$ CI $1.2-3.5)$ after treatment $(\mathrm{p} \leq 0.001)$. There was a significant increase in the baseline duration of the REM sleep stage after the therapy with the MAD ( $<<0.05)$. The amount of arousal index per hour decreased independently of the OSAS severity $(\mathrm{p}<0.001)$. Changes in baseline sleep effectiveness and in N3 sleep stage were not significant $(p>0.05)$. The MAD therapy decreased snore events $(\mathrm{p}<0.05)$.

\section{Tolerability, adherence and side effects}

Adherence to treatment was self-reported and showed that $73.0 \%$ of patients used the MAD regularly ( $>4$ days/week, $>4 \mathrm{~h} / \mathrm{night}$ ) and $27.0 \%$ used it irregularly (<4 days/week, $<4 \mathrm{~h} /$ night). 
Among the sample, $37.5 \%$ reported side effects during the first 6 months of the therapy and $8.8 \%$ after 6 months using the MAD. Most of the reported side effects were transitory and presented mild to moderate severity. The most common complaint related to temporomandibular joint (TMJ) pain and alterations in dental occlusion were reported six months after fitting the MAD. Hypersalivation, teeth discomfort, injury to the mucosa and muscle pain were also reported after fitting the appliance, but these side effects were transitory. No patient discontinued the therapy because of side effects during the evaluation period.

\section{Predictive factors}

Multivariate analyses did not identify predictive factors related to the therapy success (decrease $\geq 50 \%$ in the AHI). However, basal AHI appeared to be a significant univariate predictor related to the secondary endpoint $(\mathrm{AHI}<10 / \mathrm{h})(\mathrm{OR}=$ 1.06, IC 95\%1.00-1.13: $\mathrm{p}=0.007$ ) (Table 4).

\section{DISCUSSION}

The present study showed that MAD significantly improved the $\mathrm{AHI}$ and minimum $\mathrm{SpO}_{2}$, as well as other polysomnographic parameters among the sample. A considerable proportion of shift workers reported sleep symptoms which may be related to the work shift and OSA. A research conducted with shift workers detected that those who reported poor sleep or excessive diurnal somnolence symptoms had their working activities compromised and had four times more risk of suffering work-related accidents ${ }^{27}$. In addition, a significant relationship has been evidenced between the rates of accidents with professional long-distance drivers with AHI, thus showing that the severity of OSAS is directly proportional to the risk of accidents ${ }^{28}$.

OSA predisposes the patient to several different comorbidities, increasing the need for health services ${ }^{7,29}$. In the presentsample, many workers presented comorbidities associated with OSAS, such as hypertension, diabetes, hypothyroidism.

Table 4. Predictors of success for mandibular advancement device therapy according to the treatment response rate.

\begin{tabular}{|c|c|c|c|c|}
\hline \multirow[t]{2}{*}{ Variables } & \multicolumn{2}{|c|}{ Response rate (decrease $\geq \mathbf{5 0} \%$ in $\mathrm{AHI}$ ) } & \multirow[t]{2}{*}{ OR $(95 \% \mathrm{CI})$} & \multirow[t]{2}{*}{$\mathrm{p}$ values } \\
\hline & Yes & No & & \\
\hline Sex M/F (\%) & $58.8 / 11.2$ & $25.0 / 5.0$ & $1.02(0.25-4.18)$ & 0.973 \\
\hline \multicolumn{5}{|l|}{ Malocclusion (\%) } \\
\hline Class II & 21.3 & 10.0 & $0.56(0.15-2.03)$ & 0.382 \\
\hline Class III & 23.8 & 12.5 & $1.07(0.26-4.32)$ & 0.915 \\
\hline Maximum protrusion (mm) & $8.05 \pm 1.97$ & $8.19 \pm 1.76$ & $1.00(0.75-1.34)$ & 0.971 \\
\hline $\begin{array}{l}\text { Therapeutically protrusion } \\
(\mathrm{mm})\end{array}$ & $7.46 \pm 1.47$ & $7.21 \pm 1.14$ & $0.82(0.56-1.19)$ & 0.296 \\
\hline Mouth breathing (yes/no \%) & $27.50 / 42.50$ & $7.5 / 22.50$ & $0.49(0.15-1.54)$ & 0.226 \\
\hline Oval palate (yes/no \%) & $66.25 / 3.75$ & $28.75 / 1.25$ & $0.83(0.06-10.86)$ & 0.893 \\
\hline Arousal index (mean values) & Yes & No & & \\
\hline Sex M/F (\%) & $65.0 / 16.25$ & $18.75 / 0$ & $1.13(0.98-1.54)$ & 0.056 \\
\hline \multicolumn{5}{|l|}{ Malocclusion (\%) } \\
\hline Class I & 27.50 & 5.00 & Reference & 0.737 \\
\hline Class II & 23.75 & 7.50 & $1.18(0.25-5.61)$ & 0.645 \\
\hline Class III & 30.00 & 6.25 & $2.29(0.46-11.37)$ & 0.440 \\
\hline Overbite (mm) & $3.10 \pm 2.12$ & $2.97 \pm 2.12$ & $1.03(0.74-1.41)$ & 0.837 \\
\hline Overjet $(\mathrm{mm})$ & $2.63 \pm 1.80$ & $2.60 \pm 1.37$ & $0.96(0.60-1.54)$ & 0.915 \\
\hline Maximum protrusion (mm) & $8.13 \pm 1.88$ & $7.97 \pm 2.01$ & $0.95(0.67-1.35)$ & 0.892 \\
\hline $\begin{array}{l}\text { Therapeutically protrusion } \\
(\mathrm{mm})\end{array}$ & $7.40 \pm 1.41$ & $7.30 \pm 1.24$ & $0.85(0.53-1.34)$ & 0.837 \\
\hline
\end{tabular}

AHI: apnea-hypopnea index; CI: confidence interval; ESS: Epworth Sleepiness Scale; OR: odds ratio. 
OSAS risk assessment in workers and treatment can help reduce the burden of health care on the national system ${ }^{30}$.

Multiple factors can compromise the comparison of data between studies, including the use of different definitions regarding treatment success. The most rigorous definition of success found in studies was AHI $\leq 5 / h^{21,22}$, while the most flexible definition was $<50 \%$ of baseline $\mathrm{AHI}^{31,32}$, as being a success. Comparing our results with data from other researchers ${ }^{33}$, it can be noticed a greater reduction in the $\mathrm{AHI}$ in the present sample. This difference may be related to the different designs of MAD used in the study conducted in 2006 in which some participants used titratable appliances and others used monoblocs. In addition, even using the same appliance, different inclusion criteria and different treatment protocols might affect success rates.

The use of $\mathrm{OA}$ is currently recommended for the treatment of patients with mild or moderate OSAS (recommendation of level A $)^{33}$. However, in our study, nearly $15.0 \%$ of the participants presented severe OSAS (AHI > 30/h) and the MAD was able to significantly reduce AHI. Therefore, while OA can be less effective for the resolution of severe OSAS compared to mild/ moderate cases, patients with severe OSAS that refuse CPAP therapy can be treated with MAD ${ }^{25,30,3435}$.

The possibility of worsening in respiratory events with the use of OA was reported by other researchers ${ }^{36,37}$. A revision conducted in 1995 showed that $13 \%$ of the participants had an increase in AHI after treatment with $\mathrm{OA}^{38}$. Our results have shown a worsening among $7.5 \%$ of the sample. There are several reasons for the increase in AHI, like the lack of retention of the device in the mouth, invasion of the tongue space or increased vertical dimension caused by the MAD, inadequate degree of protrusion, in addition to factors inherent to the patient, such as non-anatomical phenotype, respiratory diseases, and weight gain during the treatment.

The literature reports that OA provide minimal improvements in minimum oxygen saturation ${ }^{20,33}$. Randomized clinical trials that evaluated 946 adult patients with OSAS treated with OA, detected that the average improvement in oxygen saturation was $3.09 \%{ }^{20}$. Our study showed similar results, since the improvement in minimum oxygen saturation varied from $1.2 \%$ to $3.5 \%$.

In 2015, it was verified that OA and CPAP do not significantly improve sleep effectiveness and architecture in adult patients with OSAS ${ }^{20}$. Although OA reduce the arousals rates in adult patients with OSAS, CPAP is more efficien $^{20}$. The present study has not found significant N3 sleep improvement, but there was significant improvement in micro arousals and REM sleep rates.

Evaluation of snorers found work-related accidents risks for heavy snorers with apnea and for OSAS patients ${ }^{39}$. In the present study, mine workers with primary snore have been referred to treatment with OA. Oral devices are effective for the treatment of primary snore in adult patients without obstructive sleep apnea ${ }^{20}$. Our results showed that after treatment, there were significant improvements in snore measured during the PSG. Moreover, it is estimated that twice as many chances of accidents are caused by carelessness and somnolence in drivers ${ }^{40}$.

OA therapy was well tolerated among the sample; the side effects were transitory, and no participant discontinued MAD therapy because of side effects during the period of evaluation. The major complaints were pain in the TMJ and alterations in the occlusion. Our results verified that the use of a MAD led to the development of TMD in a small number of patients; but as stated in the literature, these signs are generally transitory ${ }^{41}$. Patients with signs and preexisting symptoms of TMD did not present significant exacerbation of these signs and symptoms with the use of $\mathrm{OA}^{41}$.

In the long term, occlusal alterations might occur in up to $85.0 \%$ of patients ${ }^{42}$, and these alterations seem to be progressive. In the present study, a short-term evaluation was conducted, and it was observed a decrease in overbite and overjet, besides the opening of diastema in molars.

The prediction of success related to OA therapy is a key-question from both therapeutic and financial perspectives ${ }^{43}$, but the capacity to realize a precise clinical selection of patients for therapy with OA is still limited. Predictive accuracy has shown a broad variability depending on the definitions of success for the treatment ${ }^{44}$. Researchers have found some predictors of success related to treatment with $\mathrm{OA}$ such as waist circumference, obesity, overbite, class II division 2 malocclusion ${ }^{35}$. However, in the present study, only baseline AHI proved to be a significant predictor of a complete response rate (AHI $<10 / \mathrm{h}$ ) during MAD therapy. This difference might rely in the present sample size.

We acknowledge some limitations in the present study, such as the absence of a control group, but our main objective was to evaluate the effectiveness of the MAD during the treatment of mine workers with OSAS. Moreover, adhesion to treatment was based in subjective reports and the results shown are related to short term evaluation. However, as strengths it must be stated that MAD used in the sample (the Lateral-Protrusive Plaque ${ }^{\circledR}$ (PLP)) is an easy-to-adapt progressive mandibular advancement device ${ }^{26}$ that has the particularities of low cost and ease of manufacture. These characteristics facilitate its implementation in a sleep medicine program at companies and other work environments.

\section{CONCLUSION}

MAD therapy is an efficient method to treat mine workers suffering from OSAS and primary snore. The therapy may cause pain in the TMJ and alteration in occlusion, but these effects are often transient and do not 
lead to treatment discontinuation. The AHI was the only predictor of success related to MAD therapy.

Conflict of interests

The authors declare no conflicts of interest.

\section{FUNDING STATEMENT}

This work was supported by the Coordenação de Aperfeiçoamento de Pessoal de Nível Superior - Brasil (CAPES) - Finance Code 001

\section{ETHICAL APPROVAL}

Informed consent was obtained from all individual participants included in the study. The study was conducted accordingly to the principles of the Helsinki Declaration and received the approval of the Ethical Committee of Hospital Felício Rocho BHMG (CAAE - 0002.0.240.000-11). The results of the study will be disseminated by print media and through lectures and booklet distribution at mining occupational environments.

\section{REFERENCES}

1. Cho KS, Lee SH. Occupational health hazards of mine workers. Bull World Health Organ. 1978;56:205-18.

2. Donoghue AM. Occupational health hazards in mining: an overview. Occup Med (Lond). 2004;54:283-9.

3. Bauerle T, Dugdale Z, Poplin G. Mineworker fatigue: A review of what we know and future decisions. Min Eng. 2018;70:33.

4. Legault G, Clement A, Kenny GP, Hardcastle S, Keller N. Cognitive consequences of sleep deprivation, shiftwork, and heat exposure for underground miners. Appl Ergon. 2017; 58:144-50.

5. American Academy of Sleep Medicine. International Classification of Sleep Disorders, 3rd ed, American Academy of Sleep Medicine, Darien, IL. 2014.

6. Krieger J, Meslier N, Lebrun T, Levy P, Phillip-Joet F, Sailly JC, et al. Accidents in obstructive sleep apnea patients treated with nasal continuous positive airway pressure: a prospective study. The Working Group ANTADIR, Paris and CRESGE, Lille, France. Association Nationale de Traitement a Domicile des Insuffisants Respiratoires. Chest. 1997;112:1561-66.

7. AlGhanim N, Comondore VR, Fleetham J, Marra CA, Ayas NT. The economic impact of obstructive sleep apnea. Lung. 2008;186:7-12.

8. Sanna A. Obstructive sleep apnoea, motor vehicle accidents, and work performance. Chron Respir Dis. 2013;10:29-33.

9. Naismith SL, Winter VR, Hickie IB, Cistulli PA. Effect of oral appliance therapy on neurobehavioral functioning in obstructive sleep apnea: a randomized controlled trial. J Clin Sleep Med. 2005;1:374-80.

10. Peppard PE, Young T, Barnet JH, Palta M, Hagen EW, Hla KM. Increased prevalence of sleep-disordered breathing in adults. Am J Epidemiol. 2013;177:1006-14.

11. Hossain JL, Reinish LW, Kayumov L, Bhuiya P, Shapiro CM. Underlying sleep pathology may cause chronic high fatigue in shift-workers. J Sleep Res. 2003;12:223-30.

12. Karimi M, Hedner J, Zou D, Eskandari D, Lundquist AC, Grote L. Attention deficits detected in cognitive tests differentiate between sleep apnea patients with or without a motor vehicle accident. Sleep Med. 2015;16:528-33.

13. Kart L, Dutkun Y, Altin R, Ornek T, Kiran S. Prevalence of major obstructive sleep apnea syndrome symptoms in coal miners and healthy adults. Tuberk Toraks. 2010;58:261-67.

14. Tufik S, Santos-Silva R, Taddei JA, Bittencourt LR. Obstructive sleep apnea syndrome in the Sao Paulo Epidemiologic Sleep Study. Sleep Med. 2010;11:441-46.

15. Findley L, Smith C, Hooper J, Dineen M, Suratt PM. Treatment with nasal CPAP decreases automobile accidents in patients with sleep apnea. Am J Respir Crit Care Med. 2000;161:857-59.

16. Giles TL, Lasserson TJ, Smith BJ, White J, Wright J, Cates CJ. Continuous positive airways pressure for obstructive sleep apnoea in adults. Cochrane Database Syst Rev. 2006;CD001106.
17. Rotenberg BW, Vicini C, Pang EB, Pang KP. Reconsidering first-line treatment for obstructive sleep apnea: a systematic review of the literature. J Otolaryngol Head Neck Surg. 2016;45:23.

18. Donovan LM, Boeder S, Malhotra A, Patel SR. New developments in the use of positive airway pressure for obstructive sleep apnea. J Thorac Dis. 2015;7:1323-42.

19. Weaver TE, Grunstein RR. Adherence to continuous positive airway pressure therapy: the challenge to effective treatment. Proc Am Thorac Soc. 2008;5:173-78.

20. Ramar K, Dort LC, Katz SG, Lettieri CJ, Harrod CG, Thomas SM, et al. Clinical Practice Guideline for the Treatment of Obstructive Sleep Apnea and Snoring with Oral Appliance Therapy: An Update for 2015. J Clin Sleep Med. 2015;11:773-827.

21. Gotsopoulos H, Chen C, Qian J, Cistulli PA. Oral appliance therapy improves symptoms in obstructive sleep apnea: a randomized, controlled trial. Am J Respir Crit Care Med. 2002;166:743-48.

22. Engleman HM, McDonald JP, Graham D, Lello GE, Kingshott RN, Coleman EL, et al. Randomized crossover trial of two treatments for sleep apnea/hypopnea syndrome: continuous positive airway pressure and mandibular repositioning splint. Am J Respir Crit Care Med. 2002;166:855-59.

23. Vanderveken OM, Braem MJ, Dieltjens M, De Backer WA, Van de Heyning PH. Objective measurement of the therapeutic effectiveness of continuous positive airway pressure versus oral appliance therapy for the treatment of obstructive sleep apnea. Am J Respir Crit Care Med. 2013;188:1162.

24. Iber C, Ancoli-Israel S, Chesson AL Jr, Quan SF. In: American Academy of Sleep Medicine. The AASM manual for the scoring of sleep and associated events: rules, terminology and technical specifications. 1st ed. Westchester, IL: American Academy of Sleep Medicine. 2007.

25. Guimaraes MLR, Hermont AP, Guimaraes TM, Dal-Fabbro C, Bittencourt L, Chaves Junior CM. Severe obstructive sleep apnea treatment with mandibular advancement device: A case report. Sleep Sci. 2018;11:118-22.

26. Guimarães MLR, Oliveira JJM, Azevedo PG. Aparelho PLP para tratamento de ronco e apneia obstrutiva do sono. Orthod Sci Pract. 2015; 8: 113-7.

27. Drake CL, Roehrs T, Richardson G, Walsh JK, Roth T. Shift work sleep disorder: prevalence and consequences beyond that of symptomatic day workers. Sleep. 2004;27:1453-62.

28. Akkoyunlu ME, Altin R, Kart L, Atalay F, Ornek T, Bayram M, et al. Investigation of obstructive sleep apnoea syndrome prevalence among longdistance drivers from Zonguldak, Turkey. Multidiscip Respir Med 2013;8:10.

29. Leger D, Bayon V, Laaban JP, Philip P. Impact of sleep apnea on economics. Sleep Med Rev. 2012;16:455-62.

30. Phillips CL, Grunstein RR, Darendeliler MA, Mihailidou AS, Srinivasan VK, Yee BJ, et al. Health outcomes of continuous positive airway pressure versus oral appliance treatment for obstructive sleep apnea: a randomized controlled trial. Am J Respir Crit Care Med. 2013;187:879-87.

31. Kazemeini E, Braem MJ, Moorkens G, Balina S, Kastoer C, Op de Beeck S, et al. Scoring of Hypersomnolence and Fatigue in Patients With Obstructive Sleep Apnea Treated With a Titratable Custom-Made Mandibular Advancement Device. J Clin Sleep Med. 2019;15:623-8.

32. Hans MG, Nelson S, Luks VG, Lorkovich P, Baek SJ. Comparison of two dental devices for treatment of obstructive sleep apnea syndrome (OSAS). Am J Orthod Dentofacial Orthop. 1997;111:562-70.

33. Marklund M, Franklin KA, Sahlin C, Lundgren R. The effect of a mandibular advancement device on apneas and sleep in patients with obstructive sleep apnea. Chest. 1998;113:707-13.

34. Ferguson KA, Cartwright R, Rogers R, Schmidt-Nowara W. Oral appliances for snoring and obstructive sleep apnea: a review. Sleep. 2006;29:244-62.

35. Rabelo-Guimarães ML, Hermont AP, de Azevedo PG, Bastos PL, de Oliveira MTP, de Melo IM, et al. Severe obstructive sleep apnea treatment with oral appliance: the impact on obstructive, central and mixed events. Sleep Breath. 2018;22:91-98.

36. Vecchierini MF, Leger D, Laaban JP, Putterman G, Figueredo M, Levy $\mathrm{J}$, et al. Efficacy and compliance of mandibular repositioning device in obstructive sleep apnea syndrome under a patient-driven protocol of care. Sleep Med. 2008;9:762-69.

37. Ayas NT, Epstein LJ. Oral appliances in the treatment of obstructive sleep apnea and snoring. Curr Opin Pulm Med. 1998;4:355-60.

38. Ferguson KA, Ono T, Lowe AA, al-Majed S, Love LL, Fleetham JA. A short-term controlled trial of an adjustable oral appliance for the treatment of mild to moderate obstructive sleep apnoea. Thorax. 1997;52:362-8.

39. Schmidt-Nowara W, Lowe A, Wiegand L, Cartwright R, Perez-Guerra 
F, Menn S. Oral appliances for the treatment of snoring and obstructive sleep apnea: a review. Sleep. 1995;18:501-10.

40. Ulfberg J, Carter N, Talback M, Edling C. Excessive daytime sleepiness at work and subjective work performance in the general population and among heavy snorers and patients with obstructive sleep apnea. Chest. 1996;110:659-63.

41. Garbarino S, Guglielmi O, Sanna A, Mancardi GL, Magnavita N. Risk of Occupational Accidents in Workers with Obstructive Sleep Apnea: Systematic Review and Meta-analysis. Sleep. 2016;39:1211-8.

42. Perez CV, Leeuw R, Okeson JP, Carlson CR, Li HF, Bush HM, et al. The incidence and prevalence of temporomandibular disorders and posterior open bite in patients receiving mandibular advancement device therapy for obstructive sleep apnea. Sleep Breath. 2013;17:323-32.

43. Almeida FR, Lowe AA, Otsuka R, Fastlicht S, Farbood M, Tsuiki S. Long-term sequellae of oral appliance therapy in obstructive sleep apnea patients: Part 2. Study-model analysis. Am J Orthod Dentofacial Orthop. 2006;129:205-13.

44. Pelletier-Fleury N, Meslier N, Gagnadoux F, Person C, Rakotonanahary $\mathrm{D}$, Ouksel $\mathrm{H}$, et al. Economic arguments for the immediate management of moderate-to-severe obstructive sleep apnoea syndrome. Eur Respir J. 2004;23:53-60.

45. Okuno K, Pliska BT, Hamoda M, Lowe AA, Almeida FR. Prediction of oral appliance treatment outcomes in obstructive sleep apnea: A systematic review. Sleep Med Rev. 2016;30:25-33. 